\title{
PerCePÇão e RePresentaÇão EM Leibniz: A IMATERIALIDAde da MATÉRIA
}

[Perception And Representation in Leibniz: the immaAteriality of the MAtTer]

\begin{abstract}
Resumo: Este estudo apresenta a visão leibniziana sobre a percepção e sua fundamental relação com a matéria. Segundo Leibniz, a matéria, apesar de seu aspecto sólido, extenso e imóvel é, a representação mental das percepções. A razão suficiente estabeleceu como a impressão, reflexão e o desenvolvimento do ser humano como causa final à matéria, portanto, apesar de sermos condicionados racionalmente a acreditar em nosso conceito de matéria, esta é uma representação de percepções mentais (mônadas).
\end{abstract}

Palavras-chave: matéria, substância, percepção, representação, imaterialidade, apercepção.
ABSTRACT: This study showes the Leibniz's view on perception and its fundamental relationship with matter. According to Leibniz, the matter despite its solid, extense and unchangeable appearance is the mental representation of the perceptions. The reason enough established the printing, reflection and development of human beings as final cause to matter, so even though we have been rationally conditioned to believe in our concept of matter, but it is a representation of mental perceptions (monads).

KEYWORDS: matter, substance, perception, representation, immateriality, apperception.

\section{INTRODUÇÃ̃o}

Túmeras especulações foram e ainda são feitas com relação à realidade exterior. Dos vários catedráticos que ousaram investigar esse tema, destaca-se o filósofo moderno Leibniz, cuja visão intercambia os mundos físicos e metafísicos e nos conduz a uma nova leitura do mundo físico e extrafísico. Wilhelm Goltfried Leibniz (1646-1716) percebia um avanço do que ele denominou em sua Correspondência a Clarke (1672) de mecanicismo materialista defendido por renomados matemáticos: Rennè Descartes e Isaac Newton, os quais ele confrontou diretamente em suas obras: Novo Sistema da

* Universidade de São Paulo. Doutora em Ciências pela Faculdade de Medicina da Universidade de São Paulo (2015). Professora no ensino superior. Pesquisadora na área de Filosofia e Saúde, principalmente nos temas: emoções, cérebro, mente, controle das emoções, qualidade de vida, motivação e tdah. 
Natureza e da Comunicação das Substâncias, e Correspondência a Clarke, respectivamente. Também se indispõe com John Locke: Novos Ensaios sobre o Entendimento Humano. Seu propósito era frear a tendência materialista conciliando o mecanicismo com a metafísica, pois o mecanicismo puramente materialista da filosofia da natureza (ciência) vigente desdenhava a metafísica, desprezando seus princípios fundamentais. Em decorrência desse fato, Leibniz propõe um sistema da natureza respaldado em princípios metafísicos.

Em sua obra Novo Sistema da Natureza e da Comunicação das Substâncias, expõe: um agregado de mônadas externamente manifestado constitui as máquinas, essas podem ser de dois tipos: a máquina da natureza e a máquina orgânica. Observou, graças ao avanço da microscopia, que uma máquina feita pela arte do homem não é máquina em cada uma de suas partes, pois quando divididas perdiam suas funções de máquina Mas as máquinas da natureza, isto é, os corpos vivos, são ainda máquinas em suas menores partes, até ao infinito, que jamais deixariam de ser máquinas. Essa é a diferença entre a natureza e a arte, quer dizer, entre a arte divina e a nossa (cf. DM, § 64). Foi ponderando sobre essa divisão das partes da máquina da natureza ao infinito, sem, no entanto, perder suas características fundamentais, mesmo em suas menores partes, que Leibniz conclui que a matéria não pode ser a substância das coisas, afinal a substância não está propensa à divisão, mas a matéria o está, o que a impossibilitava de ser a substância das coisas. Deduz então a existência de uma substância simples (sem partes) dotada de força:

Percebi que a consideração da mera massa extensa é insuficiente e que também se deve empregar a noção de força. (...) Vi que é impossível encontrar princípios da verdadeira unidade tão somente na matéria ou em algo que seja apenas passivo. (...) Então, a fim de alcançar essas unidades reais, tive que recorrer a um átomo formal, o que pode ser denominado um ponto real e animado ou um átomo de substância, que deve conter algum tipo de forma ou atividade a fim de produzir um ser completo (SN, $\S \S 2$ e 3 ).

Ora, como era possível que a filosofia da natureza (atual ciências naturais) se utilizasse do mecanicismo integral, o qual negava a existência de qualquer outra entidade que não a material? Inconformado em ver a matéria extensa como explicação inquestionável, Leibniz se propõe a desenvolver um sistema da natureza que não se respaldasse inteiramente na matéria como substância única. Interpenetrando diversos campos, o filósofo entrelaça questões puramente físicas à recente teoria metafísica por ele formulada. Em seu sistema expugnou esse problema concebendo a existência de individualidades imateriais, forças vivas, de cuja união resultaria a matéria. Denominou-as mônadas: formas substanciais das coisas.

Em sua obra Monadologia, ele descreve a mônada como entidade perceptível, ou seja, composta de percepções que se expressam externamente; 
fundamentando seu sistema integralmente nas percepções. Como as percepções transitam no plano mental da consciência, são invisíveis e obviamente, inextensas, além de fechadas e intocáveis. Todavia, como é possível à matéria extensa, sólida e imóvel ser composta por uma substância com características tão intangíveis e incomensuráveis? Conduzirei este estudo à exposição direcionada da teoria leibniziana sobre percepção e representação de modo a justificar tal questão.

\section{PerCePÇão}

Leibniz, inovando a tendência epistemológica vigente, é contrário à concepção de percepção como oriunda das coisas externas, cujas impressões em nós se internalizam. Concebe a percepção como as próprias qualidades ou predicados dos objetos. Ou seja, não temos uma impressão da coisa exterior, possuímos internamente a totalidade das qualidades de todas as coisas: "O conjunto ordenado de predicados ou percepções que compõe a substância [a mônada], determina sua individualidade. Isso implica que todos os modos de uma dada substância referem-se à ordem dos predicados que expressam sua individualidade" (DM, § VIII).

A substância simples ou mônada é formada pela união da matéria primeira (percepção confusa) e da enteléquia. A enteléquia ou percepção clara é distinta e torna a substância ativa, logo, é força ativa, enquanto a matéria primeira ou percepção confusa, a torna passiva diante da ação de outra percepção, por isso é força passiva. A substância cuja percepção é mais clara exerce ação sobre outra substância, cuja percepção é mais confusa. Nesse sentido, o grau de clareza das percepções das mônadas pode variar e esta variação é motivada pelas apetições (tendências), e pelas causas eficientes e finais. Ou seja, as causas finais conduzem os seres a agirem segundo suas apetições e finalidades, enquanto as causas eficientes dirigem os corpos segundo as leis do movimento (cf. MO, § 79). Quanto mais a consciência deixa-se dominar pelas apetições despontadas pelo mundano, mais nos condicionamos à passividade, às percepções confusas ou vinculadas à matéria; mas quanto menos subjugada for pelas paixões, mais ativas serão nossas percepções, portanto, mais claras.

A infinita variação material existente deve-se à alteração sofrida no grau de clareza da percepção da mônada. E devido às percepções variarem constantemente, a individualidade nunca é a mesma. Por isso, a mônada, formadora dos seres existentes, possui em si mesma, qualidades que as faz diferente de qualquer outra. Ora, essas qualidades são a garantia de que, na natureza, não existe nada que seja completamente igual, podendo até ocorrer 
semelhanças, mas não indivíduos iguais, isto, por diferirem em alguns aspectos. Isso explica a vasta variedade na natureza, todas com suas peculiaridades próprias. "Com rigor matemático, a menor diferença que torna duas coisas dessemelhantes em qualquer ponto, fá-las diferentes quanto às espécies" (NE, 54 IV, vii, § 6).

Essa diversidade de percepções não deve passar totalmente despercebida pelos seres humanos, pois estes, dotados de espírito racional são capazes de apercepção. Faculdade mental capaz de notar conscientemente as percepções. Embora o ser humano devesse notar a maior parte das percepções, só as notáveis lhe serão apreendidas. Porém, além destas existem as percepções sobre as quais ele não tem consciência, denominadas de percepções inconsciente. Essas, além de inquietar-lhe o espírito, devido à falta de domínio do ser humano sobre as mesmas, não podem ser apercebidas.

\section{REPRESENTAÇÃO}

Compreendida a natureza da percepção, é preciso entender sua relação com a matéria. Como percepções ou meras qualidades podem originar a matéria? A filosofia fenomenista de Leibniz concebe que as coisas exteriores representam as percepções da mônada, mente, estabelecendo-se os pares: percepção e representação. Ambas, percepção e representação são simétricas, cada qual do seu lado, o interno (percepção) e o externo (representação) à mônada. Considerando a mônada como fechada, intocável e impenetrável, sua representação será reflexiva e simétrica, ou seja, um determinado caractere expressará somente a ele próprio, portanto não existe uma relação transitiva entre a mônada e a coisa representada .

Sendo assim, a representação monádica, ou seja, das percepções, envolve uma correspondência de um a um com a coisa representada, através de um acordo ou lei relacional, princípio da harmonia pré-estabelecida, o qual mantém a simetria entre a representação e a percepção expressa (cf. Puryer, 2006, p.10). Por exemplo: a idéia de círculo representa o círculo, porque as verdades que podem ser derivadas dela seriam, sem dúvida, confirmadas pela investigação de um círculo real (cf. Puryer, 2006, p.10). É esse relacionamento mútuo, conciliado antecipadamente em cada uma delas no universo, que produz o que denominamos comunicação. (NS, § XIV).

Devido à relação de percepção e representação entre as mônadas ser abstração da razão, não pode ser considerada real. Logo a relação é a própria harmonia existente entre as mônadas (cf. Marques, 2004). Por conectar as qualidades das coisas, no plano fenomênico, a relação é um fato indispensável e primitivo. O exemplo exposto a seguir foi citado por Hunter (1951, p. 152): Se 
uma pessoa está a 8 pés de uma cadeira, existirá um terceiro termo entre ela e a cadeira que constitui estes 8 pés. Isto quer dizer que a conexão entre a pessoa e a cadeira se dá por uma relação de 8 pés. Notamos que a relação possui função conectiva entre duas coisas. E não é necessário que o que se exprime seja semelhante à coisa exprimida, contanto que seja preservada certa analogia das relações (PS, p. 263).

Por interligar as percepções e representações a relação está presente em todo processo físico-metafísico. Logo, para existir determinada representação exterior às mônadas é necessário que elas pertençam a um grupo de mônadas compatíveis entre si, constituindo o mundo possível delas. Também as percepções que compõem a mônada devem ser compatíveis entre si. A coexistência ordenada entre esses predicados/percepções preserva a existência do sujeito. Esse inevitavelmente tornar-se-ia contraditório caso estivessem presentes nele modificações predicativas que se excluíssem reciprocamente. Existe um aspecto estruturalmente matemático, de cuja correspondência e ordenamento das percepções, conforme os princípios propostos pelo autor resultam na matéria segunda. Todos os acontecimentos, todos os movimentos, todos os efeitos, antes de se manifestarem externamente, fazem parte do conjunto de percepções que compõem as mônadas. Logo, o aspecto físico (matéria segunda) resulta de um conjunto de mônadas compatíveis entre si, embora só represente as percepções confusas (matéria primeira) da mônada de acordo com as leis das causas eficientes.

Sendo que a matéria conceituada como extensa, sólida e imóvel, nada mais é do que matéria segunda (relação entre percepções e representações de mônadas semelhantes), seria imprudente considerarmos que a matéria possa, como um agregado de "energia", ser definida como extensa, sólida e imóvel, apesar de conceitualmente defendermos essa hipótese.

"A massa da extensão, ou melhor, a coisa extensa, ou como eu prefiro a multiplicidade de coisas, eu digo que não é uma unidade, mas inúmeras unidades" (AG, p.182). "A extensão, a massa e o movimento não passam de imagens em espelhos, ou arco-íris em nuvens... Qualquer coisa na natureza afora os perceptores e suas percepções é inventada por nós, e lutamos com quimeras criadas por nossa própria mente, como que com espectros" (PS, p. 281). Logo o aspecto físico resulta de um conjunto de mônadas compatíveis entre si, mas só representa as percepções confusas dessas, portanto não revela a verdade, ele nos é útil como meio para refletirmos sobre ela (a verdade), ou para que a comprovemos. Entretanto, se acreditarmos em seu aspecto puramente material, estaremos nos iludindo com falsas noções. A razão fundamentada na matéria leva-nos a conceber meros fenômenos físicos como realidade única e indiscutível. A razão exerce uma forma de convencimento sobre nós, induzindo-nos a crer na realidade da matéria extensa. Portanto, esta 
necessita da razão para se fazer notar. Por exemplo: a dureza percebida pelos sentidos, não depende dos sentidos, mas sim da razão que nos leva a conceber a possibilidade de tal concepção. Portanto, a própria solidez é concebida pela razão, apesar de pelos sentidos, termos a impressão de sua existência. Nas palavras de Leibniz: "parece que os sentidos não podem convencer-nos da existência das coisas sensíveis sem o auxílio da razão" (NE, LII, vii, §1).

Até mesmo os acontecimentos, os quais nós julgamos resultarem de causas físicas, possuem as percepções mentais e metafísicas, como causa verdadeira. Enganamo-nos ao nos enveredar pelo caminho estritamente físico, desconsiderando a realidade metafísica que o sustenta. Não que a matéria não exista. Ela existe, mas a noção que temos sobre ela está errada. As características que atribuímos à matéria não conferem com a realidade. Desviamo-nos do real conceito de matéria quando desconsideramos as causas finais e os princípios metafísicos.

\section{CONCLUSÃo}

Como vimos, em sua constituição, a matéria é percepção, porém ainda confusa, e, somada a enteléquia, constitui a substância das coisas, a mônada. Existe uma razão suficiente para a matéria ter sido concebida dessa forma e não de outra: sua finalidade. Afinal, o conhecimento científico não deve dedicar-se a desvendar as leis da natureza utilizando-se somente das causas eficientes, mas deve também ater-se as causas finais (cf. Okruhlik, 1982). Utilizando-se de seu próprio método o autor fez uma avaliação da real finalidade da matéria, a razão suficiente de sua existência, a partir de uma investigação à cerca da finalidade do ser.

A finalidade do ser é o seu desenvolvimento mental, é aguçar sua capacidade de apercepção, de reflexão. Pois em seu aspecto metafísico, o ser traz consigo as qualidades (percepções) que deposita externamente. Em sua face física, o ser observa-se nesse exterior representado. Por ser constituído de percepções claras sobre tudo, mas não conseguir notar com distinção as coisas por ela expressa, é que o homem conhece o mundo de maneira confusa. Se acaso tivesse os órgãos dos sentidos penetrantes a ponto de notar as menores partes das coisas, ele não as notaria de maneira confusa, mas acharia tudo organizado. E quanto mais apurada fosse a sua sensibilidade, maior seria a nitidez com que observaria a realidade, chegando a notar que a divisão da matéria é infinita (cf. PR, p. 22).

Assim sendo, a matéria externalizada, por ser representação de percepções, não tem condições de ser definida como geralmente o é: extensa, sólida e imóvel. Vimos que sua extensão é atributo das percepções confusas 
somada ao nosso condicionamento racional, do mesmo modo que sua solidez. Sua característica de imobilidade é por ignorarmos que ela, tal como um ponto flutuante, cujo movimento sempre estará entrando em sua próxima posição precisamente definida.

Outro fato é que a matéria como fenômeno, pode ser infinitamente compósita, ou seja, podemos dividi-la ao infinito. Leibniz é tenaz quanto à multiplicidade ou composições representadas pelas percepções, quando afirma que não há corpos ou coisas materiais como o senso comum reconhece, ou seja, sem energia. Se a matéria subsistisse sem a substância imaterial, aquilo que chamamos corpo não passaria de cadáver (cf. Ross, 2001, p. 102). Portanto é a mente que expressando suas percepções confusas nos dá, mediante o auxilio da sensação e da racionalização, a impressão comum de matéria. A substância simples, que é mente, fundamenta a existência da matéria, que não passa de fenômeno.

O sistema leibniziano, como uma teia, transpassa os princípios metafísicos pela trama do mundo fenomênico. Apesar de distinguir ambos os níveis, físico e metafísico, o autor os entre - apóia, atribuindo às coisas materiais a faculdade perceptiva. Logo, o aspecto real da matéria é imaterial, ou seja, energia em movimento, sem extensão e solidez; é uma representação expressa pelo ser.

A metafísica não destitui a importância da matéria; ao contrário, vai ao encontro de sua finalidade: o desenvolvimento do ser, a clarificação de suas percepções confusas, pois a matéria não contém a verdade, serve somente de "veículo" a sua confirmação. A finalidade da matéria, quando a sentimos, é nos levar à reflexão, afinal não poderíamos desenvolver o conhecimento se não pensássemos alguma coisa. Em suma, quanto maior a consciência sobre as percepções, maior será nosso aprimoramento mental e melhores serão as correspondentes representações no exterior.

\section{REFERÊNCIAS BIBLIOGRÁFICAS}

\section{Fontes primárias e abreviações}

NS LEIBNIZ G. W.: Sistema Novo da Natureza e da Comunicação das Substâncias e Outros Textos. Belo Horizonte: Editora da UFMG, 2002.

NE LEIBNIZ, G. W.: Novos Ensaios sobre o Entendimento Humano. Tradução: Luiz João Baraúna. Coleção Os Pensadores. São Paulo: Editora Abril, 1978.

CC LEIBNIZ, G. W.: Correspondência a Clarke. Tradução: Luiz João Baraúna e Calos Lopes de Mattos. Coleção Os Pensadores. São Paulo: Editora Nova Cultural, 1988.

AG LEIBNIZ G. W.: Philosophical Essays. Edited and Translated: R. Ariew and D. Garber, Indianapolis: Hackett, 1989. 
PR LEIBNIZ G. W.: A "Protogaea": Uma teoria sobre a Evolução da Terra e a Origem dos Fósseis. Ramos, M. C., Teixeira, D., Papavero, N: São Paulo: Ed. Fapesp, 1997.

DM LEIBNIZ G. W.: Discurso de Metafísica e Outros Textos. Tradução, apresentação e notas de Tessa Moura Lacerda. São Paulo: Martins Fontes, 2004.

MO LEIBNIZ G. W.: Monadologia. Tradução, apresentação e notas de Tessa Moura Lacerda. São Paulo: Martins Fontes, 2004.

NG LEIBNIZ G. W.: Princípios da Natureza e da Graça fundados na Razão. Tradução, apresentação e notas de Tessa Moura Lacerda. São Paulo: Martins Fontes, 2004.

PS LEIBNIZ G. W.: Die philosophisheim Schriten. Vol. VII, Berlin: Ed. Gerhardt, VII, Berlin, Halle: 1963.

TH LEIBNIZ G. W.: Teodicea: Ensayos Sobre La Bondad De Dios, La Libertad Del hombre Y El Origen Del Mal. Edición electrónica de www.philosophia.cl / Escuela de Filosofía Universidad, ARCIS, 1710.

\section{Fontes secundárias}

FICHANT, M.: Leibniz e as máquinas da natureza, in: Dois Pontos - Revista do Departamento de Filosofia da Universidade Federal de São Carlos. São Carlos, 10/2005. v. 2 , n 1.

GABER, D.: Leibniz: physics and philosophy, in: Cambridge History Of Seventeenth - Century Philo. USA: Ed. Cambridge, 1997. p. 270 - 356.

HUNTER, G. Monadic Relations. In: The natural philosophy of Leibniz. D. Reidel Publishing Company, 1982.p. $151-170$.

LACERDA, T. M.: A Expressão em Leibniz. Tese de Doutorado. São Paulo: Universidade de São Paulo, 2005.

MARQUES, E. Possibilidade, Compossibilidade e Incompossiblidade em Leibniz. Belo Horizonte: Kriterion, 2004. v.45, n⿳0109, p. 175 - 187.

OKRUHLIK, K. The Status of Scientific Laws in the Leibnizian System, in: The natural philosophy of Leibniz. D. Reidel Publishing Company, 1982. p. 183 -204.

PURYER, S. M. Perception and representation in Leibniz. Tese de Doutorado. University of Pittsburgh, 2006. p. $8-58$.

RESCHER, N. G. W. Leibniz's Monadologia: An Edition for Students. Londres: United Kingdom by Routledge, 1928.

ROSS, M. D. Leibniz. São Paulo: Ed. Loyola, 2001.

RUSSELL, B.: A Filosofia de Leibniz. São Paulo: Ed. Nacional, 1968.

SLEIGH, R. C. Jr.: Leibniz and Arnauld: a commentary on their Correspondence. New Haven: Yale University Press, 1990.

SWOYER, C. Leibnizian Expression. Journal of the History of Philosophy, 1995, v.33, p.65-99. 